\title{
O DISCURSO CONCEITUAL DA DEFICIÊNCIA INTELECTUAL E DA CULTURA ESCOLAR PRESENTE NO CURSO DE FORMAÇÃO DA FUNDAÇÃO PESTALOZZI DO BRASIL EM 1953
}

\section{THE CONCEPTUAL DISCOURSE OF INTELLECTUAL DEFICIENCY AND SCHOOL CULTURE PRESENTED IN THE TRAINING COURSE OF THE PESTALOZZI FOUNDATION OF BRAZIL IN 1953}

\author{
Cibele Braga Ferreira Nascimento* \\ Laura Maria da Silva Alves**
}

\begin{abstract}
Resumo: Objetiva-se analisar os discursos de ordem conceitual e da cultura escolar do curso de formação da Fundação Pestalozzi do Brasil. Trata-se de uma pesquisa documental, tendo como fonte o livro de registros de Cruz (1998) e a entrevista com a Prof. Blandina Alves Torres no Jornal a Folha do Norte em 1954. Os dados foram analisados com base na análise do discurso de Mikhail Bakhtin (1992), levando em consideração a rede de significados. Encontrou-se discursos de ordem conceitual identificando a criança com deficiência intelectual como excepcional, destacando a educabilidade e integração social dos mesmos; além de se observar a cultura escolar por meio de suas práticas, organização curricular e estratégias metodológicas. Destaca-se a relevância de pesquisas em História da Educação que aborde a criança com deficiência intelectual, por meio de instituições educativas, a fim de compreender nos discursos a ideologia e a materialidade, inserida na realidade sócio-cultural e histórica.
\end{abstract}

Palavras-chave: História da Educação. Criança com Deficiência Intelectual. Fundação Pestalozzi.

Abstract: This research objective to analyze the speeches of conceptual and school culture of the training course of the Pestalozzi Foundation of Brazil. This is a documentary research, and as a source book of records of the Cruz (1998) and the interview with Teacher Blandina Alves Torres in the newspaper Folha do Norte in 1954. The documents were analyzed based on discourse analysis of Mikhail Bakhtin (1992), taking into consideration the network of meanings. Met speeches of conceptual order identifying the child with intellectual disabilities as exceptional, highlighting the educability and social integration of them; besides observing the school culture through their practices, curricular organization and methodological strategies. It highlights the importance of research in History of Education that addresses the

\footnotetext{
* Docente da Faculdade de Fisioterapia e Terapia Ocupacional da Universidade Federal do Pará. Possui graduação em Terapia Ocupacional pela Universidade do Estado do Pará (2010), pós-graduação em Desenvolvimento Infantil pela mesma universidade (2010), Mestrado em Educação pelo PPGE da UEPA (2014) e é Doutoranda em Educação pelo PPGE da UFPA.

** Professora de Psicologia da Educação da Universidade Federal do Pará. Bacharel em Psicologia pela Universidade da Amazônia (1984) e graduada em Formação de Psicólogo pela Universidade da Amazônia (1986). É especialista em Educação e Problemas Regionais na Amazônia pela Universidade Federal do Pará (1988), Mestre em Letras pela mesma universidade e Doutora em Psicologia da Educação pela PUCSP (2003).
} 
child with intellectual disabilities, through educational institutions, in order to understand the discourse ideology and materiality, part of the socio-cultural and historical reality.

Key-words: History of Education. Children with Intellectual Disabilities. Pestalozzi Foundation.

\section{Introdução}

Segundo Ariés (1981) pode-se afirmar que a concepção de infância iniciou-se no século XIII, porém no século XVI o universo infantil ainda era bastante negligenciado, com ofertas de atendimentos precários com altos índices de mortalidade e morbidade infantil, sendo a infância representada pelo estigma da pobreza, abandono e caridade, fazendo-se emergir conceitos como: infância desvalida, infância abandonada, infância delinquente, além da categoria "menor" (SCHUELER, [s/d]).

Tais adjetivações caracterizavam as divergências e diversidades que envolviam o termo infância e, consequentemente, demonstravam a complexidade de iniciativas educativas destinadas a sujeitos em condições plurais e desiguais da experiência humana. Dessa forma, questiono: a deficiência enquanto aspecto que evoca a diversidade humana, era contemplada? Se as crianças sem atrasos no desenvolvimento já encontravam dificuldades em acessar projetos educacionais, o que dirá das crianças com deficiência?

Segundo Ahmad (2009) a partir do século XIX e XX, a infância começa a ser reconhecida e a ocupar um lugar de destaque para a família e para a sociedade, ou seja, passou-se a reconhecer a criança não somente como um adulto em miniatura, mas como um ser humano que também necessita de cuidados e que possui direitos básicos, representando a infância como uma categoria social. Assim ratifico a importância de se compreender a infância não somente pela perspectiva biológica, mas também histórica.

Victor ET AL (2012) afirmam que para esta construção histórica do conceito de infância foi fundamental a tomada de consciência da alteridade das crianças em relação aos adultos e a fundação de instituições. Porém tal separação histórica teve reflexos diretos nas representações e, inclusive, nos conceitos e identidade da infância, pois estes estavam mais atrelados às características que os destinguem dos adultos do que pelas suas próprias características de infante. 
Tal fato também é visualizado na historia da infância das crianças com deficiência, pois como afirma Plainsance (2005) estas eram reconhecidas mais pelas representações da deficiência do que pelas características da infância com suas eventuais particularidades, ou seja, se via mais as características da deficiência do que a criança que por ventura tinha uma alteração no seu desenvolvimento.

Dessa forma, Victor ET AL (2012) aponta esta situação como problema, afirmando, inclusive, que é em decorrência dessas generalizações que se conhece pouco sobre as particularidades dessa infância negada e/ou negligenciada, pois o investimento histórico foi o de identificar as representações dessa infância e não como os modos de vida eram desenvolvidos a partir deste recorte de infância.

[...] Tanto a infância quanto a deficiência são temáticas que lidam hoje com as mesmas consequências de uma um contexto social mais amplo. A ideia de infância e criança, e a representação de deficiência na sociedade ainda se mostram de forma caricaturesca e genérica, desconsiderando uma das especificidades da condição humana, que é a diferença (OLIVEIRA apud VICTOR ET AL 2012.p. 139).

Diante desta breve contextualização é possível perceber que a infância passa a adotar uma importância no contexto sócio-cultural apenas no século XIX e XX, após séculos de negligencia, quisá pensar sobre as crianças com deficiência, de maneira especial a com deficiência intelectual, e as suas formas de ser infante. Tais evidências apontam para a indissobilididade do tempo histórico com os conceitos e formas de compreensão da deficiência, com as formas de abordagem e educabilidade e de construção da sociedade, uma vez que "O conceito tem uma relação estreita com as concepções sociais, políticas, econômicas e ideais que nortearam cada período da história" (GARGHETTI; MEDEIROS; NUENBERG, 2013.p.101).

É também nos séculos XIX e XX, a partir desta concepção ampliada da infância é que surge a necessidade de expansão nas redes sociais de suporte para a educação formalizada dos mesmos. Assim, são constituídas as primeiras instituições educativas de cuidado e assistência às crianças.

Sanfelice (2007.p.77) conceitua as instituições a partir de uma concepção multiderecional, pois compreende que: "uma instituição escolar ou educativa é a síntese de múltiplas determinações, de variadíssimas instâncias (política, econômica, cultural, religiosa, 
da educação geral, moral, ideológica, etc.) que agem e interagem entre si”. Assim adentrar na investigação acerca das instituições de educação de crianças, de maneira especial das com deficiência intelectual é adentrar não só uma estrutura física, mas principalmente ideológica constituída de discursos de diversas intâncias que se materializam nas práticas pedagógicas e na cultura escolar.

Como afirma Bueno (2011.p. 170) "as primeiras instituições para crianças deficientes surgem na segunda metade do século XVIII, em Paris, voltadas exclusivamente para crianças cegas e surdas" e se assemelhavam aos hospícios que funcionavam em regime de internado, com apenas duas diferenças: as instituições tinham a perspectiva de ressocialização por meio de ações que estimulassem a independências das crianças e àquelas que pertecessem à famílias com possibilidades, a instituição funcionava em regime aberto.

No Brasil as primeiras instituições surgiram na segunda metade do século XIX, atendendo a mesma clientela, porém com um ideário segregacionista. Após este primeiro momento de construção da educação especial no Brasil, surge um novo período marcado do início do século XX até meados da década de 50, onde se observa uma disseminação das instituições de educação especial pelo país tal como a Fundação Pestalozzi, ao mesmo tempo em que a escola regular busca homogeneizar as turmas, de modo a excluir os alunos-problema e encaminhá-los as instituições especiais que cresciam no país (BUENO, 2011).

Segundo a Federação Nacional das Associações Pestalozzi [s/d] o início do Movimento Pestalozziano no Brasil se deu em 1926 na cidade de Porto Alegre com a criação do Instituto Pestalozzi de Canoas, no Estado do Rio Grande do Sul, pelo Professor Thiago Würth e foi criado com foco no atendimento das pessoas com dificuldades de aprendizagem, sendo em 1928 fundada pelo mesmo educador a Sociedade Pedagógica Pestalozzi.

Em 1929 ao Brasil, a educadora russa Helena Antipoff, a convite do Governo do Estado de Minas Gerais, trazendo o legado de informações e aprendizagem obtido com Johann Heinrich Pestalozzi enfatizando o trabalho na reabilitação e na formação de recursos humanos no atendimento à pessoa com deficiência. Segundo Cruz (1988), Helena Antipoff trazia uma sólida formação moral e científica e era professora da cadeira de psicologia experimental.

Posteriormente a instituição se expandiu para outros Estados com a implantação das Associações Pestalozzi em Minas Gerais, no Rio de Janeiro e em São Paulo e a constituição 
de cursos de formação para o atendimento e a educação de crianças com deficiência intelectual. A Sociedade Pestalozzi do Brasil promovia o curso de especialização intitulafo: "Educação de excepcionais retardados mentais" no Instituto Nacional de Estudos Pedagógicos (INEP) no Rio de Janeiro.

Tais cursos tinham como objetivo apresentar os fundamentos teórico-metodológicos da educação de crianças com deficiência intelectual, a partir da cultura escolar da Fundação Pestalozzi do Rio de Janeiro (capital do Brasil na época e sede promotora das formações). Na sétima edição do curso, no ano de 1953, a professora normalista Blandina Alves Torres, foi a representante do Estado do Pará. Após a conclusão do curso a referida professora retorna à capital Paraense e é entrevistada pelo Jornal a Folha do Norte, em Janeiro de 1954, onde descreve o que viveu nos cursos de formação, destacando em seu discurso a concepção ideológica, organizacional e operacional da instituição.

Assim, este estudo objetiva analisar o discurso educacional no Curso de Formação da Sociedade Pestalozzi do Brasil acerca da criança com deficiência intelectual e da cultura escolar da fundação, a partir da entrevista histórica da Prof. Blandina Torres ao jornal "A Folha do Norte" em 1954.

\section{Metodologia}

Este estudo se fundamenta na Nova História, pois compreendo que o objetivo de pesquisa visa não só descrever aspectos de uma história oficial ou dos fatos e dos personagens heróicos, mas compreender que na dimensão da vida cotidiana novos sujeitos, fatos, instituições, etc., constituem-se história, fugindo da concepção tradicional, e buscando apreender o contexto sócio-histórico mais amplo.

Em oposição à Historiografia Tradicional surgiu um novo olhar historiográfico, com um sentido mais amplo, complexo e abrangente sobre os espaços sociais destinados à educação escolar, atribuindo muita importância às suas singularidades e particularidades. [...] Essa renovação sugere que novos questionamentos se cruzem com o alargamento das problemáticas, a diversidade dos contextos e aos modelos e práticas educativas. Observamos também uma grande preocupação da nova historiografia em rever o conceito de história institucional, levando em consideração a problematização das instituições na sua relação com a comunidade envolvente. Neste sentido, o itinerário seguido pelos pesquisadores que se preocupam em construir interpretações a respeito das instituições educativas se pauta em apreender 
elementos que possam conferir às mesmas, um sentido histórico no contexto social de sua época (OLIVEIRA; GATTI JUNIOR, 2002.p. 73).

Destaco a íntima relação das (re)organizações sociais com os processos educativos que nela e para ela são constituídos, pois ao trabalhar com a perspectiva da história das instituições não pretendo partir da leitura historicista da educação (NORONHA, 2007), apenas narrando os fatos, mas sim inserindo-os na realidade sócio-cultural estudada, afim de contribuir para a construção da identidade histórica da instituição em questão, pois: "Por mais sedutoras que sejam essas pesquisas, não se pode aceitar que a descrição pormenorizada da de uma instituição escolar deixe de levar o leitor à compreensão da totalidade histórica" (BUFFA, 2007.P. 155).

Também caracterizada como uma pesquisa documental. Sá-Silva, Almeida e Guindani (2009.p. 2) destacam a relevância das pesquisas do tipo documental ao afirmarem que:

o uso de documentos em pesquisa deve ser apreciado e valorizado. A riqueza de informações que deles podemos extrair e resgatar [...] possibilita ampliar o entendimento de objetos cuja compreensão necessita de contextualização histórica e sociocultural.

Vale destacar a escolha da Fundação Pestalozzi enquanto instituição, se deu em função da mesma ser uma das pioneiras no Estado do Pará na atenção à crianças com deficiência do tipo intelectual, reconhecendo a influência de tal instituição no contexto da cultura local e da estrutura social da época.

As fontes primárias utilizadas nessa pesquisa são: 1. O livro de registro de Cruz (1988)- livro este que contém registros da história de criação da Fundação Pestalozzi no Pará, documentos importantes como atas de reuniões, documentos de sessão de posse (terreno onde a instituição foi construída), fluxograma e organograma da instituição, listas dos fundadores da instituição no Pará, Lista dos primeiros funcionários, lista dos primeiros alunos, imagens dos setores da instituição, imagens de eventos onde a instituição teve participação e registro das atividades desenvolvidas em cada setor da instituição. Neste trabalho se utilizará apenas os registros históricos, relatados no livro acerca da fundação da Instituição; 2. A entrevista da prof. Blandina Alves ao Jornal a Folha do Norte de 04 de Janeiro de 1954, encontrada no acervo de microfilmados do Centro Cultural Trancredo Neves (CENTUR) em Belém, Pará, Brasil. 
Após a organização das fontes, foi feita a análise mediante a análise do discurso tendo como base a leitura Backtiniana, pois Mikhail Bakhtin (1992) compreende que os discursos não podem ser deslocados dos sujeitos, ou seja, para se compreender os significados do discurso de alguém se faz necessário compreender quem é este alguém, que contextos sócioculturais os mesmos frequentam e que ideologias os constituem, uma vez que não há texto sem contexto, não há produção teórica sem que esta esteja entrelaçada com a vida.

Bakhtin foi tão relevante dentro de suas produções que Barros (1997.p. 27) afirma que o mesmo "influenciou ou antecipou as principais orientações teóricas dos estudos sobre o texto e o discurso desenvolvidos, sobretudo, nos últimos trinta anos", em virtude, principalmente, da forma como o autor concebia o texto colocando-o como objeto das ciências humanas, além da defesa do princípio dialógico.

O pioneirismo de Bakhtin em ampliar o estudo do texto pela lingüística, ou seja, das mínimas unidades que constituem uma frase, para compreender o texto ou o discurso como uma produção do ser humano deslocou, portanto, sua análise para as ciências humanas, pois compreende que "o homem não só é conhecido através dos textos, como se constrói enquanto objeto de estudos nos ou por meio dos textos" (BARROS, 1997.p. 28)

A partir da leitura Bakhtiniana optei por trabalhar com a categoria rede de significados, a fim de compreender os processos constituídos sócio-culturalmente nas e por meio da interação mútua existente entre contexto-sujeito, uma vez que: "A perspectiva da rede de significações propõe que o desenvolvimento humano se dá dentro de processos complexos, imerso em uma malha de elementos de natureza semiótica" (ALVES, 2005.p. 200)

Portando compreendo que a obra Bakhtiniana pode auxiliar a significar um determinado discurso político-social e educacional de uma data instituição, de um programa curricular, das práticas acadêmicas, das representações de infância, da cultura material escolar, entre outros, sendo, portanto, uma abordagem teórico-metodológica consistente e rica para se utilizar dentro dos estudos que tenham como eixo a história da educação, da história da infância e da história das instituições, daí a escolha do referencial Bakhtiniano da análise do discurso como referencial teórico-metodológico deste estudo.

A análise do discurso me permitiu construir categorias a partir das redes de significados constituídos dos discursos polifônicos das fontes documentais utilizadas, a saber: 
O Sujeito Histórico e o Contexto Político-Social; Rede de significado da Deficiência Intelectual; e Prática Pedagógica e Cultura Escolar. Assim, a seguir será transcrito o texto da entrevista da Professora Blandina Alves, realizada ao Jornal a Folha do Norte (imagem 1), de modo a facilitar o entendimento aos leitores, seguida do debate e discussão nas categorias de análise suscitadas.

\section{Imagem 1: Entrevista sobre a experiência de formação na Fundação Pestalozzi}

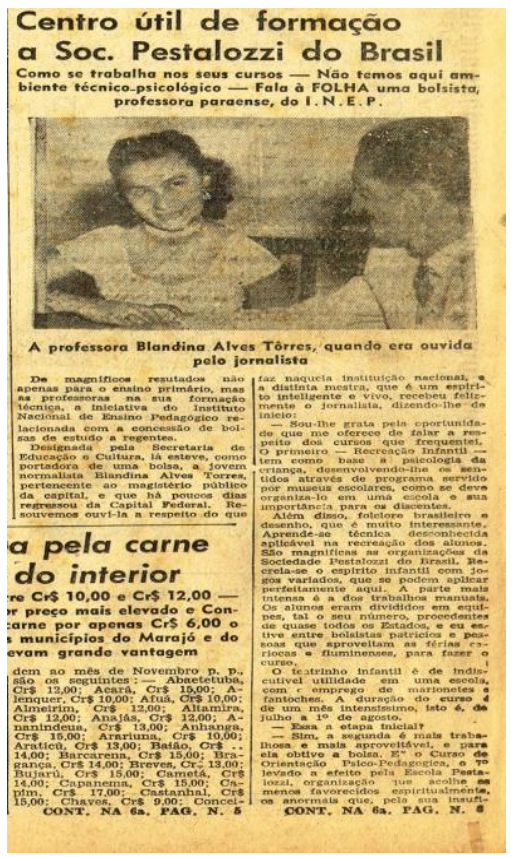

Fonte: Jornal A Folha do Norte, 1954.

FOLHA DO NORTE

4 de Janeiro de 1954

CENTRO ÚTIL DE FORMAÇÃO A SOC. PESTALOZZI DO BRASIL

Como se trabalha nos seus cursos- não temos aqui ambiente técnico-psicológico

- fala à FOLHA uma bolsista, professora paraense do INEP.

De magníficos resultados não apenas para o ensino primário, mas as professoras na sua formação técnica, iniciativa do Instituto Nacional de Ensino Pedagógico relacionada com a concessão de bolsas de estudo a regentes.

Designada pela Secretaria de Educação e Cultura, lá esteve como portadora de uma bolsa, a jovem normalista Blandina Alves Tôrres, pertencente ao magistério público da capital, e que há poucos dias regressou da capital federal. Decidimos ouvi-la a respeito do que faz naquela instituição nacional e, a distinta mestra, que é um espírito inteligente e vivo, recebeu felizmente o jornalista, dizendo-lhe de início:

- Sou-lhe grata pela oportunidade que me oferece de falar a respeito dos cursos que freqüentei. O primeiro- Recreação Infantil- tem como base a psicologia da criança, desenvolvendo-lhe os sentidos através de programa servido por museus 
escolares, como se deve organizá-lo em uma escola e sua importância para os discentes.

Além disso, folclore brasileiro e desenho, que é muito interessante. Aprende-se técnica desconhecida aplicável na recreação dos alunos. São magníficas as organizações a Sociedade Pestalozzi do Brasil. Recreia-se o espírito infantil com jogos variados, que se podem aplicar perfeitamente aqui. A parte mais intensa é a dos trabalhos manuais. Os alunos eram divididos em equipes, tal o seu número, procedentes de quase todos os Estados, e eu estive entre bolsistas patrícios e pessoas que aproveitavam as férias cariocas e fluminenses, para fazer o curso.

O teatrinho infantil é de indiscutível utilidade em uma escola com o emprego de marionetes e fantoches. A duração do curso é de um mês intensíssimo, isto é, de julho à $1^{\circ}$ de agosto.

-Essa é a etapa inicial?

- Sim, a segunda é a mais trabalhosa e aproveitável e para ela obtive a bolsa. É o curso de orientação psico-pedagógico, o $7^{\circ}$ levado a efeito pela Escola Pestalozzi, organização que acolhe os menos favorecidos espiritualmente, os anormais que, pela sua insuficiência mental, são chamados excepcionais. Tiveram, os bolsistas contato direto com eles, principalmente no terreno escolar, estudando-lhes as dignidades para efeito de método de ensino a ser empregado. É todo fundamentado em psicologia intuitiva da criança e do adolescente, e em estudo, que só pode ser ligeiro, das deficiências ou distúrbios da linguagem.

-Diante disso professora,o que dizer da instrução primária daqui e de outros centros brasileiros?

- Os nossos defeitos professor, resultam disso: não temos ambiente técnico-pedagógico, equipe organizada e pronta para atender a casos que se manifestem comumente nas casas de ensino. Mas, continuávamos, além disso, moças fazem estágio familiarizando-se, nas turmas especiais, mediante curso de aprendizagem, com menores e adultos divididos em três grupos: crianças, adolescentes e adultos. A base é o trabalho manual, o ensino é vivo, e a criança tem a possibilidade de conhecer a motivação. Para os maiores, o artesanato é que é a oficina. Até os retardados por força da comunidade produzem. De mistura dessa motivação do estágio recebíamos outras vocações, como disciplina indispensável na melhor compreensão do problema que se estava encarando, elementos da psico-terapia e psiquiatria. Minha impressão foi ótima. Lá há de tudo, inclusive recurso para corrigir distúrbios mentais, sociológico, educacional e técnicos.

Sociedade Pestalozzi do Brasil onde passei horas aproveitáveis, é ambiente, pobre em que mais se remedeia e mais se cria do que se adquire. $O$ próprio material é feito pelos alunos e professores. Não há riqueza, não há pompa, mas simplicidade no corpo docente. Todos trabalham no horário integral das $8 \mathrm{~h}$ as 18horas, estimulando os bolsistas. O curso é interessante e poderá ser mais útil se feito em menos tempo. A exigüidade reduz a utilidade dos resultados.

\section{O sujeito histórico e o contexto político-social}

Bakhtin enquanto teórico de base sócio-histórica defende a concepção de que o sujetio se constitui não somente a partir de sua estrutura psico-biológica, mas imerso em um contexto, ou seja, defende a perspectiva sociológica como constituidora do homem. Sendo que este 
homem interage e se envolve na cultura e no meio sócio-histórico pela linguagem, daí a ampla importância dada pelo autor às questões do texto/discurso.

O sujeito é visto por Bakhtin como sendo constituído e imbricado em seu meio social, sendo, portanto, permeado pelos discursos que o circundam. Ou seja, cada sujeito é um sujeito híbrido, uma arena de conflito e confrontação de vários discursos que o constituem, sendo que cada um desses discursos, ao se confrontar com os outros, exerce uma hegemonia sobre eles. É através das interações sociais que Bakhtin desvenda como o sujeito apreende o discurso de outrem. (ALVES, 2000.p.203).

Assim é importante iniciar a análise dos dados carecterizando o sujeito-históico, apresentando brevemente a Professor Blandina Alves Torres, de modo a identificar a rede de significados constituída dos seus discursos. A professora em questão era uma jovem normalista, professora paraense do Instituto Nacional de Estudos e Pesquisas (INEP). A professora era de origem humilde, do interior do Estado, onde concluiu seu ensino fundamental. Seus pais faziam questão da continuidade dos estudos escolares e mudaram-se para a capital, Belém do Pará, a fim de oferecerem aos filhos oportunidades de educação. Assim a professora deu continuidade à sua formação na educação básica, chegando ao ensino superior, concluindo a graduação pelo Núcleo Pedagógico Integrado (NPI), atualmente chamado de Escola de Aplicação. Devido sua origem humilde a professora via no estudo freqüente e no bom rendimento uma forma de honrar o sacrifício dos pais que abandonaram fazendas no interior para se submeter a vida paupérrima na Capital.

Em decorrência do seu currículo e boas notas durante a graduação, foi publicamente premiada, sendo um dos prêmios a nomeação para professora na cadeira do Estado. Devido sua juventude, disposição e competência foi indicada pela Secretaria de Educação e Cultura para estudar na capital brasileira, na época o Rio de Janeiro, na sétima edição do curso da Sociedade Pestalozzi, no ano de 1953.

Após seu retorno para Belém a professora concede a referida entrevista com vistas a divulgar o que viveu no período de formação. O primeiro enunciado do discurso da professora é de agradecimento pela oportunidade à ela concedida de fazer o curso, reconhecido como privilégio de poucos, uma vez que a professora foi a única bolsista do INEP e da Secretaria de Educação do Estado a receber tal investimento, caracterizando o seu destaque no meio acadêmico e o seu perfil profissional, já que o curso era um investimento técnico afim de ter 
possíveis retornos práticos na realidade educacional paraense. Tal discurso de gratidão da prof. Blandina Torres traz significados da ordem da meritocracia, pois o próprio jornalista a representa como "distinta mestra de espírito inteligente e vivo", o que sugere ao leitor do jornal não somente a competência técnica da professora, mas também sua habilidade pessoal que seriam a base para a constituição de práticas educativas voltadas à população em questão tão carente na realidade paraense.

A posição e o papel político que a professora desempenhava, bem como o investimento financeiro que recebera justificam a pouca abordagem de pontos críticos para a constituição de tais práticas na educação paraense, observados no discurso discreto que a mesma faz e brevemente interrompe: “(...) nossos defeitos professor, resultam disso: não temos ambiente técnico-pedagógico, equipe organizada e pronta para atender a casos que se manifestem comumente nas casas de ensino", optando por destacar no discurso mais as suas vivencias no processo de formação do que problematizar a infra-estrutura para a educação de crianças com deficiência no Estado .

\section{Rede de significado da deficiência intelectual}

Para Bakhtin “o sujeito é essencialmente histórico. Sua fala é produzida a partir de um determinado lugar e de um determinado tempo. A narrativa do sujeito é um recorte das representações de um tempo histórico ou de um espaço social bem definido" (ALVES, 2000.p. 211), portanto no discurso divulgado no jornal é evidente a concepção de deficiência intelectual entendida e trabalhada na Fundação Pestalozzi do Brasil, porém tais discursos só podem ser compreendidos á luz do seu tempo, de modo a não se fazer interpretações e/ou inferências anacrônicas.

Dessa forma a criança com deficiência intelectual é compreendida como: "menos favorecidos espiritualmente, os anormais que, pela sua insuficiência mental, são chamados excepcionais”. Em uma única frase esta infância é adjetivada de quatro formas diferentes, todas com significados próprios que constituem a rede da compreensão da deficiência intelectual. 
A primeira expressão "menos favorecidos espiritualmente", traz a palavra espiritualidade como base, sendo esta compreendida não somente como uma relação com algo transcedental ou com entidades superiores, como se compreendia na antiguidade (a deficiência como consequiência da ausência da espiritualidade e/ou religiosidade; como castigo divino pelas transgressões do homem), mas também compreendida como sentido de vida, pois como afirma Portal (2004.p.69) “espiritualidade como um sentido mais amplo da vida que contempla amor, reverência e confiança".

$\mathrm{O}$ autor defende o sentido do amor quando aborda a disponibilidade para estar com o outro, abrindo-se a conhecer novas pessoas, um amor inclusivo que rompe com os estigmas da incapacidade. A concepção de Portal se assemelha a própria concepção de Pestalozzi que tinha como base do seu fazer pedagógico o amor, também influenciado por princípios cristãos (BORGES, [s/d]).

Pestalozzi entendia que a criança se desenvolve de dentro para fora, ou seja, se opunha à concepção de que a função do ensino é preenchê-la de informação. Para o educador, um dos cuidados principais do professor seria de acompanhar de maneira atenciosa os estágios de desenvolvimento da criança, suas aptidões e necessidades, de acordo com as diferentes idades. Sendo, portanto, a função principal do ensino a de levar as crianças a desenvolverem suas habilidades naturais e inatas, sendo o amor a base de tal investimento, pois "Segundo ele, o amor deflagra o processo de auto-educação"(FERRARI, 2011. p. 1).

Para Portal (2004) a reverência é compreendida como o reconhecimento das próprias limitações e a tomada de decisão para superá-los, fator que fomenta o processo educativo para pessoas com deficiência por compreender que limitação e/ou dificuldade funcional não deve ser agente de estagnação, ao contrário deve ser agente motivador e de superação, pois como afirma Vygotsky (apud VITOR , 2012. p. 144): "não se deve perceber na criança com deficiência apenas o defeito, os 'gramas' de doença e não se notar os 'quilogramas' de saúde que a criança possui”.

A confiança segundo Portal (2004.p.69) é a tomada de posição no mundo por meio do envolvimento com o que se faz, sendo este também um ideário Pestalozziano pois versa sobre o empoderar a criança com deficiência intelectual a assumir um lugar no mundo por meio do processo educativo e dos cuidados disponibilizados pela própria instituição. 
Outro termo utilizado para caracterizar o sujeito em questão foi "anormal" que se refere diretamente a noção de normalidade que segundo Oliveira (2004) a priori trazia o significado de perpendiculariedade, referindo idéia de certa semelhança, porém a partir do século XIX a palavra normalidade se assemelhou a noção de padrão, sendo o padrão ideal definido e caracterizado pelas figuras mitológicas, portanto, tudo o que fugia ao ideal de perfeição era considerado padrão de anormalidade. Assim aqueles que fogem a normalidade, como o são as crianças com deficiência, são os excluídos pelos ideais eugenistas de todos os direitos e serviços, incluindo a educação.

As ideias eugenistas persistiram no século $\mathrm{XX}$, ao ponto de se terem intelectuais que defendiam o controle de natalidadede com fins da preservação social, autorizando o Estado a matar os indesejados socialmente tais como os "pobres, sifilíticos, epilépticos, dipsomaníacos, aleijados, criminosos e degenerados" (DAVIS, 2006.p. 8), ou seja, as crianças com deficiência estavam inseridas na roda dos excluídos e dos condenados à morte.

Assim, a infância da pessoa deficiente morre antes mesmo de trazer seu caráter infantil. É ainda no nascimento que essa não infância era decidida, o que gera uma dificuldade para o estudo da infância da pessoa com deficiência, pois estamos num espaço da história em que essa infância parece não ter existido. (VICTOR ET AL 2012.p. 141)

Para Davis (2006.p. 3) “o 'problema' não é a pessoa com lesão; o problema é a maneira que a normalidade está sendo construída para criar o 'problema' da pessoa com deficiência". É interessante este movimento por perceber que a pessoa com deficiência saiu da condição de negligenciada ou silenciada, para a condição de ser reconhecida, porém tratada à distância, como um verdadeiro problema, daí a preocupação inicial de acolhimento e de educação para essa infância ser assumida por instituições privadas que constituíram a educação especial fora das salas comuns.

Assim foi com a Fundação Pestalozzi que iniciou o Movimento Pestalozziano no Brasil em 1926 na cidade de Porto Alegre com a criação do Instituto Pestalozzi de Canoas, no Estado do Rio Grande do Sul, pelo Professor Thiago Würth e foi criado com foco no atendimento das pessoas com dificuldades de aprendizagem, sendo em 1928 fundada pelo mesmo educador a Sociedade Pedagógica Pestalozzi (FEDERAÇÃO NACIONAL DAS ASSOCIAÇÕES PESTALOZZI [s/d]). 
Por fim o termo "insuficiência mental" abordado no discurso evidencia uma certa aproximação com o conceito de deficiência intelectual, utilizado atualmente, porém sugere alguns equívocos com a também próxima associação da deficiência intelectual com o transtorno mental, que são diferentes na sua concepção e característica. O primeiro refere-se a dificuldades de ordem funcional ocasionadas por alterações nas funções cognitivas (memória, associação, atenção, sequenciamento, entre outros), enquanto que a segunda refere alterações funcionais decorrentes de alterações psicológicas e psiquiátricas (alterações no humor, na tomada de consciência, no juízo critico, na interação social, entre outros).

$\mathrm{Na}$ Inglaterra, no século XIV, é outorgada a lei chamada “Da prerogativa Regis" por Eduardo II, onde se é registrado pela primeira vez a tentativa em distinguir a deficiência mental e a doença mental, caracterizadas como: "a primeira, 'loucura natural', pessoas que sofriam de idiotia permanente e, a segunda, 'lunática', aquelas que sofriam de alterações psiquiátricas transitórias. O doente mental tinha direito aos cuidados sem perder os bens" (RODRIGUES, 2008.p.9).

É evidente que naquele contexto histórico os estudos sobre a deficiência intelectual estavam em processo de desenvolvimento, o que justifica certa confusão de compreensão das diferenças de causalidades e consequentemente de abordagem interventiva e educacional a ser realizada, tal como se observa no seguinte relato: “(...) como disciplina indispensável na melhor compreensão do problema que se estava encarando elementos da psico-terapia e psiquiatria. Minha impressão foi ótima. Lá há de tudo, inclusive recurso para corrigir distúrbios mentais, sociológico, educacional e técnicos".

Todos os três termos utilizados no discurso da professora trazem uma rede de significações complexa que determina a forma pelos quais tais crianças eram classificadas naquele respectivo contexto sócio-histórico: "excepcional". Porém o que esses termos evidenciam é a representação negativa que se tinha dessa infância, com conteúdos ideológicos que referendavam a improdutividade e a não educabilidade dos mesmos. Tal descrença pode ser observada no seguinte discurso: "Até os retardados por força da comunidade produzem".

Assim era comum assemelhar a criança com deficiência, de maneira especial a intelectual, à improdutividade e ao não pertencimento social, resultando na exclusão das mesmas, uma vez que as "representações da deficiência (denominações e classificações, assim como suas conseqüências sobre as instituições e as práticas) é caracterizada pela assimilação 
da criança portadora de deficiências a uma criança mais jovem" (PLAISCANCE, 2005, p.409).

Assim faço um destaque no pioneirismo da Fundação Pestalozzi em propor uma ideologia de confrontamento à lógica da época, oferecendo um serviço educacional e terapêutico que não só defendia como explorava a aprendizagem e a produtividade da criança com deficiência intelectual, por meio de uma organização institucional e curricular que potencializasse a aprendizagem, por meio de estratégias e recursos lúdicos com vistas a favorecer a apropriação do conhecimento; além do movimento opositor à reclusão, pois enquanto se buscava esconder e silenciar essa infância, devido a herança histórica da segregação e em decorrência das concepções eugênicas de normalidade, a Fundação Pestalozzi priorizava a Integração educacional, a fim de construir pontes sociais para a criança com deficiência e seu entorno.

O conceito de integração educacional, embora ainda estivesse atrelado à concepção da normalização, pois compreendia que todas as crianças deveriam ter acesso à educação em normais condições, independente de sãs especificidades e, portanto, deveriam ser tratadas e educadas de forma comuns, devendo-se elas mesmas a ser adaptar ao ambiente e a metodologia da escola; foi um conceito que à luz do período histórico (embora atualmente não seja o preconizado), favoreceu a luta e o engajamento de crianças com deficiência intelectual nos espaços sociais e de direito, garantindo inclusive um reconhecimento das instituições que priorizavam tais práticas, inclusive a Fundação Pestalozzi.

\section{Prática pedagógica e cultura escolar}

A professora na entrevista também descreve os cursos que participou na Fundação Pestalozzi, evidenciando a abordagem prática com que a instituição cuidava e educava a criança com deficiência intelectual, sendo tal curso de formação o embrião para a constituição de instituições educativas com este fim no Estado do Pará.

A professora inicia pelo curso de recreação infantil, destacando a base psicológica e a utilização de metodologias diversas como o desenho, teatro infantil e trabalhos manuais aplicados à realidade brasileira valendo-se do folclore, por exemplo, além da divisão de 
tarefas de acordo com a diferença etária dos participantes. Também há destaque no discurso da professora a utilização de técnicas antes desconhecida pela mesma no curso de orientação psico-pedagógica.

A perspectiva lúdica e interacionista defendida pela Fundação Pestalozzi em sua cultura escolar era herança de estudos de intelectuais do século XIX, que buscaram sintetizar pela primeira vez uma estrutura metodológica de compreensão e cuidado da criança com deficiência intelectual, sendo Jean-Jacques Gaspar Itard (1774-1832), médico do Instituto Nacional de Surdos- Mudos em Paris (Essa nomenclatura já foi extinta, utilizando-se apenas a palavra "Surdo"), em 1800 o primeiro a constituir um programa sistemático de Educação Especial, quando retratou o trabalho com as crianças selvagens, sendo o trabalho clássico o desenvolvido no início do século XIX, com o menino Victor de Aveyron, com quem conviveu e trabalhou por cinco anos.

Segundo Mazzotta (2011) Itard tinha uma base sensorialista, organicista e médica e compreendia que foi a carência de socialização e da educação que assemelhou a criança ao comportamento animalesco e, que portanto, um meio para a cura do comportamento animal seria a oferta das carências observadas. Assim, Itard defendia a educabilidade, pois compreendia que o homem era reflexo daquilo que o meio o fazia ser.

Neste mesmo período, inaugurando uma leitura visionária de mundo e de direito, Johann Heinrich Pestallozzi surge, levantando a bandeira da educação pública, como direito de toda criança, inclusive das naturalmente excluídas como as advindas das classes pobres, pois compreendia que o papel da educação se inseria na formação moral, política e religiosa, a fim de produzir uma autonomia intelectual para a independência produtiva, por isso o "ensino escolar deveria propiciar o desenvolvimento de cada um em três campos: o da faculdade de conhecer, o de desenvolver habilidades manuais e o de desenvolver atitudes e valores morais" (RODRIGUES, 2008.p.14).

Destaco o Pestalozzi como intelectual que provoca na história uma reflexão: se o direito à educação é de todos os excluídos (mesmo que a priori a leitura de mundo do autor tenha se voltado para a divisão de classes), não seriam as crianças com deficiência, crianças excluidas e como tal crianças de igual direito ao ensino público? Tal reflexão é que permite a associação deste intelectual aos movimentos de luta pelo direito da criança com deficiência, 
incorporando-o como ícone, colocando seu nome em um das maiores instituições de educação e cuidado de crianças com deficiência intelectual no país.

Portanto a partir das experiências e das influencias ideológicas dos referidos intelectuais a educabilidade de crianças com deficiência, de maneira especial a intelectual, passa a se tornar mote e investimento de estudos e pesquisas, a partir da construção de métodos e técnicas que favorecessem a aprendizagem. Então se utilizava estratégias didáticas que pudessem motivar as crianças pelo uso da ludicidade, principalmente com o uso de cores, música, e a construção de recursos didáticos e pedagógicos, além da idéia de treinamento pedagógico sistemático (MAZZOTTA, 2011).

Percebo no discurso da professora a valorização do fazer didático da Fundação, tanto na sistematização do processo educativo quanto na fundamentação teórica escolhida, além do reconhecimento de um processo de formação técnica de base interventivo, onde os bolsistas tiveram a oportunidade de não apenas debaterem teoricamente sobre o tema, mas de sistematizar os fundamentos teórico-metodologicos nos estágios junto as escolas onde as crianças eram educadas e cuidadas.

Faço destaque a este discurso por compreender a rede de significados de base temporal sobre o qual o mesmo é constituído, pois data-se do ano de 1954. Segundo Brasil (2008) apesar da Instituição Pestalozzi ter sido fundada no Brasil no início do século XX no ano de 1926, tal instituição se restringia a poucas cidades o que tornava a abordagem teóricometodológica da instituição uma novidade para os jovens normalistas que faziam o referido curso, além de demonstrar que nesse período não havia nenhuma prática ou instituição educativa com estes fins na região Norte do país. Portanto, os conhecimentos apreendidos no curso foram de fundamental importância para a elaboração de um novo saber: a educação e o cuidado dos chamados retardados mentais.

Por fim a professora encerra a entrevista tornando claro nos seu discurso que embora a instituição tenha um renome nacional, desenvolva práticas inovadoras, tenha cursos de formação e seja bem organizada estrutural e funcionalmente, a instituição não possui grande investimento financeiro sendo mantida por ajudas e pelos trabalhos desenvolvidos pelos próprios sujeitos constituintes de tal prática como se observa no seguinte discurso: “é ambiente, pobre em que mais se remedeia e mais se cria do que se adquire. O próprio material é feito pelos alunos e professores. Não há riqueza, não há pompa, mas simplicidade 
no corpo docente. trabalham no horário integral das 8 h as 18horas (...)”. Esse discurso se assemelha com o fazer pedagógico de Pestalozzi, influenciador da fundação, como se observa no trecho da obra de Borges ([s/d].p.3) :

Pestalozzi dedicou seus esforços, tempo, recursos financeiros e sua própria família a vivencia de suas idéias pedagógicas. Fundou orfanatos e educou meninos e meninas pobres e abandonados, procurando formar o caráter de cada um. Mais do que ensinar a ler, escrever e transmitir outros conteúdos considerados relevantes para a formação intelectual, Pestalozzi interessava-se pela formação integral, pela construção da personalidade individual da criança.

Observo que se constituiu uma rede de significados baseados em ideologias centradas na formação do sujeito, de maneira especial da criança com deficiência intelectual, por meio de uma pedagogia do amor, por meio do envolvimento e doação de si, que seja capaz de superar com alteridade as limitações impostas pela deficiência, empoderando-se de métodos, técnicas, recursos e uma base teórica consistente e diversa levando em consideração especificidades, a fim de empoderar tais sujeitos de um lugar social que lhe é de direito e que os eduque não somente pelo viés formativo, mas também para a constituição da personalidade.

Segundo Alves (2000) a rede de significações para Bakhtin é compreendida por meio da tríade: eu-para-mim que representa como me percebo aos olhos dos outros; eu-para-osoutros que representa como os outros me vêem; outro-para-mim que representa como percebo o outro. Assim a tríade auxilia a pensar e refletir sobre as bases que um determinado discurso traz, buscando trazer à consciência de quem fala, as concepções ideológicas, políticas, sociais, religiosas, econômicas, entre outras, contidas em um determinado discurso.

Tal fator me chama atenção por perceber que no encontro do eu (Blandina ao relatar sua experiência) com os outros (leitores da entrevista) houve a constituição da rede de significações. Pois foi do referido encontro do texto com o contexto de mães de crianças com deficiência intelectual e de educadores paraenses que a entrevista ecoou.

As práticas pedagógicas e formas de organização revelam a identidade institucional da Fundação Pestalozzi do Brasil, que constitui a "cultura escolar, que vai desde a história do fazer escolar, práticas e condutas, até os conteúdos, inseridos num contexto histórico que realiza os fins do ensino e produz pessoas"(OLIVEIRA; GATTI JUNIOR, 2002.p.75). Dessa forma, entendo que as redes de significados presentes tanto no conceito de deficiência 
intelectual quanto nas práticas pedagógicas são constituídas pelo contexto sócio-histórico, representadas pelos intelectuais, pela construção do saber sobre a deficiência, além da conjuntura política e social que formavam o emaranhado de componentes de ordem contextuais que reverberavam na construção da educação especial no Brasil, ecoando (por meio da entrevista que teve circulação regional) no Estado do Pará e servindo como fonte de inspiração para a constituição da Fundação Pestalozzi no referido Estado.

\section{Considerações finais}

Nesse estudo foi possível problematizar a infância da criança com deficiência intelectual, por meio de uma instituição educativa e de cuidado de referência, pioneira no século XX, a Fundação Pestalozzi. Como toda instituição a Fundação traz em seu corpo ideológico e prático discursos que se materializam no fazer cotidiano de educar e cuidar da criança com deficiência intelectual. Discursos esses propagados em sua estrutura curricular nos cursos de formação de professores acontecidos na cidade do Rio de Janeiro.

Apresento um marco histórico para a constituição da Fundação Pestalozzi no Estado do Pará a presença de uma professora normalista no curso de formação no ano de 1953, que não só viveu experiências ricas e inéditas, como também retorna à Capital com um desejo de difundir o aprendizado, e em uma entrevista faz ecooar a forma de trabalho ea concepção ideológica da Fundação Pestalozzi no Brasil.

Foi possível destacar no estudo os discursos de conceituação da deficiência intelectual, além de evidenciar as práticas pedagógicas da Fundação Pestalozzi por meio de sua organização e estratégia metodológica, compreendendo os mesmos como um construto histórico-social que necessita ser compreendido à luz de um tempo e lugar. Assim ressalto o pioneirismo da Fundação Pestalozzi em incentivar a educabilidade e na integração da criança com deficiência intelectual, rompendo com o paradigma da exclusão.

Destaco neste trabalho a leitura Bakhtiniana que compreende o discurso como constituído das interações sócio-históricas e formado por redes de significados oriundos de diversas ordens, sendo os discursos interrelacionados ao sujeito que fala. Bakhtin é um autor ainda pouco explorado nos eixos história da educação, história da infância e história das instituições, porém que traz grande contribuição para uma análise discursiva contextualizada e dialógica, sendo um caminho teórico-metodologógico consistente e inovador para pesquisas 
com estas temáticas. Busca-se, portanto, contribuir com a comunidade científica a fim de iniciar maiores aproximações e romper trincheiras epistemológicas.

\section{Referencias Bibliográficas}

$\begin{array}{lcccr}\text { AHMAD. Laila } & \text { Azize } & \text { Souto, Um breve Histórico da } & \text { Infância e da } & \text { Instituição de } \\ \text { Educação } & \text { Infantil. } & \text { P@rtes } & \text { (São Paulo). } & \text { Junho de }\end{array}$ 2009. Disponível em<www.partes.com.br/educacao/historicoinfancia.asp>. Acesso em 13 de Jan de 2015.

ALVES, Laura Maria Silva Araújo. A rede de significações na constituição do sujeito para Bakhtin. In: VIEIRA JUNIOR, Otaviano; OLIVEIRA, Damião; ABREU, Waldir (orgs.). dossiê filosofia da educação. Rev. Multidisciplinar do Núcleo de Pesquisa UFPA, v.2, n.3, 2005.p. 199-212.ARIÉS, Philippe: História Social da Criança e da Família, Tradução: Dora Flaksman Rio de Janeiro: Guanabara, 1981.

BAKHTIN, Mikhail. Marxismo e filosofia da linguagem. São Paulo: HUCITEC, 1992.

BARROS, Diana Luz Pessoa de. Contribuições de Bakhtin às teorias do discurso. In: BRAIT, Beth (org.). Bakhtin, dialogismo e construção do sentido. Campinas, SP: UNICAMP, 1997.p. 27-38.

BORGES, Inez Augusto. Johan Heinrich Pestalozzi e suas contribuições para a reflexão sobre a educação cristã $[\mathbf{s} / \mathbf{d}] . \quad$ Encontrado em: http://www.mackenzie.br/fileadmin/Chancelaria/GT2/Inez_Augusto_Borges_II.pdf. acesso em 13 de Jan de 2015.

BRASIL, MINISTÉRIO DA EDUCAÇÃO. Política de Educação especial na perspectiva da inclusão. Secretaria de Educação: 2008.

BUENO, José Geraldo Silveira. A produção social da identidade anormal. In: FREITAS, Marcos Cezar de (org.). História social da infância no Brasil. 8 ed. São Paulo: Cortez, 2011. P. 163-186.

BUFFA, Ester. Os estudos sobre instituições escolares: organização do espaço e propostas pedagógicas. In: NASCIMENTO, Maria Isabel Moura; SANDANO, Wilson; LOMBARDI, 
José Claudinei; SAVIANI, Dermeval (orgs.). Instituições Escolares no Brasil: conceito e reconstrução histórica. Campinas: São Paulo, 2007.p.151- 164.

CRUZ, Miguel Evangelista Miranda da. Fundação Pestalozzi do Pará: a Educação especial no processo de integração social. Belém: CEJUP, 1988.

DAVIS, L. J. A construção da normalidade: a curva do sino, o romance e a invenção do corpo incapacitado no século XIX. Trad. José Anchieta de Oliveira Bentes. In: DAVIS, L. J. (Ed.). The disability Studies Reader. 2nd ed. New York: Routledge, 2006, p. 3-16. [texto digitalizado]

FEDERAÇÃO NACIONAL DA FUNDAÇÃO PESTALOZZI. O movimento Pestalozziano. [S/D]. encontrado em: http://www.fenapestalozzi.org.br/. Acesso em 12 de Jan de 2015.

FERRARI, Marcio. Johann Heinrich Pestalozzi. 2011. Encontrado em: http://educarparacrescer.abril.com.br/aprendizagem/pestalozzi-307416.shtml. Acesso 14 de Jan de 2015

FOLHA DO NORTE. CENTRO ÚTIL DE FORMAÇÃO A SOC. PESTALOZZI DO BRASIL. 1954. Encontrado em: CENTUR- setor micofilmados. Acesso: jun de 2014.

GARGHETTI, Francine Cristine; MEDEIROS, José Gonçalves; NUERNBERG, Adriano Henrique. Breve História Da Deficiência Intelectual. Revista Electrónica de Investigación y Docencia (REID), 10, Julio, 2013, 101-116.

MAZZOTTA, Marcos José Silveira. Educação especial no Brasil: História e políticas publicas.6ed.São Paulo Cortez, 2011.

NORONHA, Olinda Maria. Historiografia das instituições escolares: contribuição ao debate metodológico. In: NASCIMENTO, Maria Isabel Moura; SANDANO, Wilson; LOMBARDI, José Claudinei; SAVIANI, Dermeval (orgs.). Instituições Escolares no Brasil: conceito e reconstrução histórica. Campinas: São Paulo, 2007.p.165-173.

OLIVEIRA, Ivanilde Apoluceno de. Saberes, imaginários e representações na educação especial- a problemática ética da "diferença" e da exclusão social. Petrópolis, RJ: Vozes, 2004.

OLIVEIRA, Lúcia Helena M. M.; JÚNIOR, Décio Gatti. História das instituições educativas: um novo olhar historiográfico. Cadernos de História da Educação - v. 1. - n 1 jan./dez. 2002. P. 73-76. 
PLAISANCE, Eric. Denominações da infância: do anormal ao deficiente. Rev. Educ. Soc., Campinas, vol. 26, n. 91, p. 405-417, Maio/Ago. 2005 p.407-417.

PORTAL, Leda Lísia Franciosi. Espiritualidade: uma dimensão essencialna experiência significativa da vida. In: TEIXEIRA, Evilasio Francisco; Muller, Marisia Campio; SILVIA, Juliana Dors. (orgs.). Espiritualidade e qualidade de vida. Porto Alegra: EDIPUCRS, 2004. p. 68-78.

RODRIGUES, Olga Maria Piazentin Rolim. Educação especial: história, etiologia e conceitos e legislação vigente. In: RODRIGUES, Olga Maria Piazentim Rolim; MARANHE, Elisandra André. Práticas em educação especial e inclusiva na área da deficiência mental. Bauru : MEC/FC/SEE, 2008.

SANFELICE, J.L. História das Instituições escolares. In.: NASCIMENTO, M. I. M.; SANDANO, W.; LOMBARDI, J. C.; SAVIANI, D. (orgs.). Instituições escolares no Brasil. Conceito e reconstrução histórica. Campinas, SP: Autores Associados: HISTEDBR; Sorocaba, SP: Uniso; Ponta Grossa, PR: UEPG, 2007, pp.75-93.

SÁ-SILVA, Jackson Ronie; ALMEIDA, Cristóvão Domingos de; GUINDANI, Joel Felipe. Pesquisa Documental: pistas teóricas e metodológicas. Rev. Brasileira de História e Ciências Sociais. V.1, n.1, 2009. P. 1-15.

SCHUELER, Alessandra Frota Martinez. Internatos, asilos e instituições disciplinares na história da bducação brasileira. Encontrado http://www.educacao.ufrj.br/artigos/n7/numero7-

artigo_1_internatos_asilos_e_instituicoes_alessandra_f_m_de_schueler.pdf. acesso em: 13 de Jan de 2015.

VICTOR, Sônia Lopes. A Criança com deficiência: um Estudo Sobre Infância, Cultura, Inclusão E Subjetividade. XVI ENDIPE - Encontro Nacional de Didática e Práticas de Ensino - UNICAMP - Campinas - 2012. P. 25-32. 